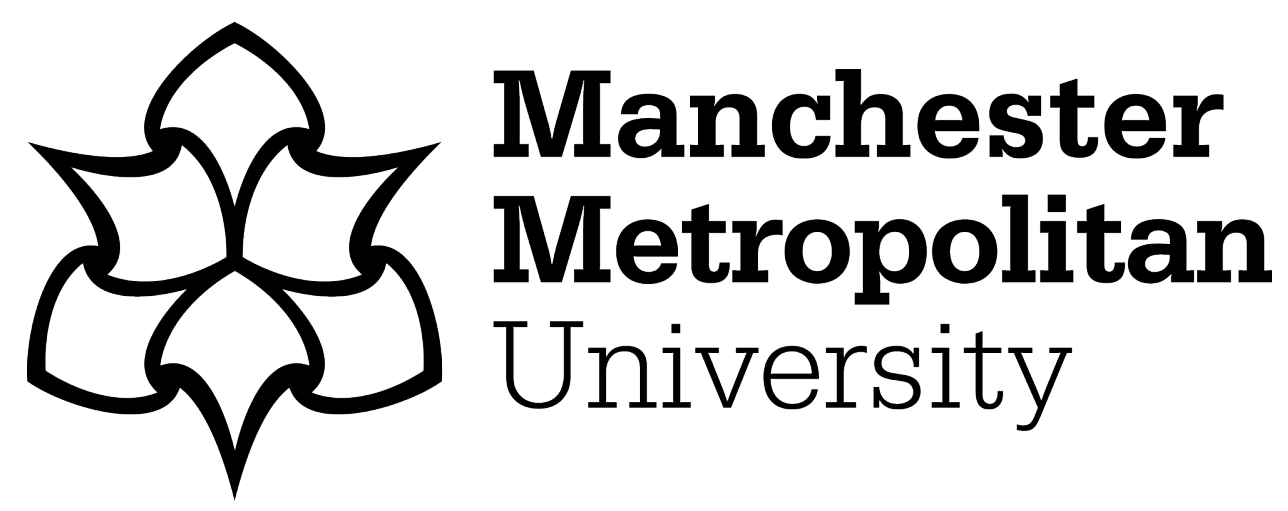

Liskiewicz, TW ORCID logoORCID: https://orcid.org/0000-0002-0866-814X, Kubiak, KJ, Mann, DL and Mathia, TG (2019) Analysis of surface roughness morphology with TRIZ methodology in automotive electrical contacts: Design against third body fretting-corrosion. Tribology International, 143. p. 106019. ISSN 0301-679X

Downloaded from: https://e-space.mmu.ac.uk/624361/

Version: Accepted Version

Publisher: Elsevier BV

DOI: https://doi.org/10.1016/j.triboint.2019.106019

Please cite the published version 


\title{
Analysis of surface roughness morphology with TRIZ methodology in automotive electrical contacts: design against third body fretting-corrosion
}

\author{
T.W. Liskiewicz ${ }^{1}$, K.J. Kubiak², D.L. Mann³ ${ }^{3}$ T.G. Mathia ${ }^{4}$ \\ ${ }^{1}$ Department of Engineering, Manchester Metropolitan University, Manchester M15 6BH, UK \\ ${ }^{2}$ School of Mechanical Engineering, University of Leeds, LS2 9JT Leeds, UK \\ ${ }^{3}$ Systematic Innovation, EX39 5QW Bideford, UK \\ ${ }^{4}$ Laboratoire de Tribologie et Dynamique des Systèmes École Centrale de Lyon, 69134 \\ Ecully Cedex, France
}

\begin{abstract}
Electrical connectors for motor vehicles are essential for the safe and efficient operation of a vehicle. However, their durability is limited by fretting induced corrosion. This type of surface damage is observed between two interconnected surfaces exposed to vibration and temperature variations. Such conditions occur during normal vehicle operation and cause two parts of an electrical contact to move at high frequency and with a small amplitude of movement relative to each other. This damages both surfaces, creates wear particles and then oxidizes them in the air. This causes an oxide layer to form at the interface, isolating the two surfaces and increasing the electrical resistance, resulting in contact failure. This study shows how the service life of electrical contacts can be extended by a surface design approach that controls the metal interface and ensures low contact resistance. The approach combines surface morphology with the progressive process of interfacial oxidation. A strong relationship between surface roughness and electrical contact resistance was observed and is elucidated in this study. Theory of Inventive Problems Solving (TRIZ) was used to identify surface texturing as a viable option to increase durability of automotive electrical connectors.
\end{abstract}


Keywords: electrical contact; fretting; surface texture; oxidation; tribologically transformed structure; TRIZ

\section{Introduction}

In recent decades, electronic systems have become an integral part of all types of vehicles. New functions, new devices and the increasing complexity of electronics require hundreds of meters of cable to connect the different devices and ensure the integrity of the entire system. This results in a large number of electrical connections with more than 400 connectors and 3000 electrical contacts on board in a single vehicle [1]. The comfort and safety of vehicle users depend on the reliability of the electronics and the durability of the electrical contacts. However, failures can occur and it is estimated that up to $60 \%$ of all electrical problems in the car are due to deterioration of electrical contacts due to fretting corrosion [2].

Fretting corrosion is a specific damage process observed between two surfaces exposed to vibration and temperature variations [3]. Such conditions occur during normal vehicle operation and cause two parts of an electrical contact to move at high frequency and with a small amplitude of movement relative to each other - usually up to a hundred micrometers [4]. This damages both surfaces, creates wear particles and then oxidizes them in the air. This causes an oxide layer to form at the interface, isolating the two surfaces and increasing the electrical resistance, resulting in contact failure. Such a situation can present a safety risk and very often requires costly repair resulting from a simple and inexpensive failure of technical components.

In order to overcome the challenges mentioned above, surface physicists and tribologists have been working for years to acquire a basic understanding of the performance of electrical contacts. The theory of electrical "spreading resistance" was advanced by Rayleigh in 1871, Kohlrausch in 1900, Browning in 1906 and Binder in 1912. With studies of carbon microphones showing that the decrease in resistance is not due to a reduction in the specific 
resistance of carbon, as Thomas Edison recommended, but to changes in the type of contact between carbon granules, Ragnar Holm has introduced a systematic modern science of electrical contacts. In its Electric Contacts Handbook, published in 1958, Holm establishes a link between the contact resistance and the specific resistance of the contact and the diameter of the connections inside the contact [5]. The 2000 edition of "Elektrische Kontakte: Theory and Application" by Ragnar Holm, \& Else Holm, prefaced by J.B.P. Williamson, is a completely revised and rewritten edition of the 1958 classic [6]. Since then, the measurement of "spreading resistance", now more commonly known as "shrink resistance" or simply electrical contact resistance, has become the main method for studying the aspects of metal contacts. In the early 1980s, two review papers were published by the Rabinowicz research groups of the Illinois Institute of Technology [7] and Antler of AT\&T Laboratories [8]. The particular aspect of metal contacts involving the physics of solids under various dynamic conditions of thermal, mechanical and electromagnetic loading has been studied by Mathia at Lyon University for telemetry applications [9]. These studies summarize current knowledge and show that noble metals have a higher resistance to fretting corrosion and a lower contact resistance over time than non-noble metals. Noble metals, mainly gold, have been used in satellite systems, rockets, F1 cars and other high-performance racing cars, but their cost is prohibitive for the rest of the automotive sector.

Since the 1980s, several research groups have studied various aspects of the durability of basic electrical contacts and attempted to extend their service life. The research group in Lyon, France, focused on studying load conditions and showed the relationship between sliding behaviour at the interface and the service life of electrical contacts [10,11]. In Great Britain, McBride's Southampton electromechanical group studied in detail the relationship between surface damage and intermittent contact resistance errors [12,13]. This group also performed unique in situ measurements of temperature, humidity and pressure in automotive connectors, which provided a better understanding of the actual operating conditions of these components [14]. In recent years, a research group at Yonsei University in South 
Korea has been very active in this field, publishing a dozen articles on tinned contacts covering charging conditions, wear analysis, lubricants, current charging, contact temperature and numerical methods [15-26].

All this research has led to a better understanding of the deterioration of fretting corrosion of electrical contacts in automobiles, but the overall performance of non-noble surfaces is still not satisfactory. In this paper, we study the influence of the intentional texture of the surface on the fretting corrosion resistance of electrical contact components.

\section{Methodology}

\subsection{TRIZ}

TRIZ methodology in its classical form was developed by the Soviet inventor Genrich Altshuller and his associates after the Second World War. In Russian (теория решения изобретательских задач), teoriya resheniya izobretatelskikh zadatch, literally means: "theory of the resolution of invention-related tasks" and is a problem-solving, analysis and forecasting tool [27]. The 'intentional surface texturing' is consistent with the oftentimes counter-intuitive recommendations of the TRIZ methodology. In studying the differences between 'good' and 'bad' innovation attempts, the 75-year, 10-million case-study evolution history of TRIZ has revealed a number of patterns of evolution. Sitting behind these patterns is governing meta-pattern in which the overarching direction of evolution success is in a direction of increasing 'ideality' (defined as the benefits delivered by a system, divided by the sum of negative attributes and side-effects). To date, thirty-eight of the more granular patterns have been revealed [28]. One of the patterns relates to the evolution of surfaces Fig. 1.

The first stage of the Trend involves the use of "smooth" surfaces, it being generally held practice that smooth is a sound output aspiration for any manufacturing process. The second 
evolution stage, however, suggests that there will be a functional benefit attributable to adding protrusions to surfaces. In the case of the dimples in golf-balls, for example, the advantage might be a reduction in drag. Ribbed road-markings offer the additional benefit of providing drivers with a warning rumble-noise should they inadvertently stray outside the recommended lane markings. Adding tread-marks on tyres serve to evacuate water and increase grip. Adding protrusions to lenses offers the opportunity - as observable in lenticular designs - to alter light focusing properties that allow the lens to be made much smaller. The benefits of adding protrusions are many; the evolution to making use of protrusions seems to be a universal. Tribologists are increasingly learning a corresponding series of new benefits achievable by adopting more three-dimensional protrusions, as illustrated in the third stage of the Fig. 1. Trend. Nature, however, is the master of the exploitation of 3D surfaces. Think, for example, the nature of shark-skin as a solution for reducing drag. Or the leaves of the Lotus plant which give rise to low-surface energy and hence effective 'self-cleaning' properties. Or the 'gratings' found on several species of butterfly which offer a variety of colour-changing properties.

A fourth - and currently 'final' - evolution stage involves addition of 'active' elements to a surface. In this sense, what TRIZ attempts to do for engineers and scientists is offer future solution 'clues'. TRIZ cannot say what specific kind of active element might be relevant to a given situation, but by offering the generic clue, it enables users to interrogate knowledge repositories like the various patent databases in order to identify which active elements are available and how they are being used. When the UK glass manufacturer Pilkington, for example, were looking at the future evolution of their sheet glass products, glass was very much at the first stage of the trend: the job of the process engineer was to make glass as smooth as possible. By adding micro-scale 'protrusions', the first 'self-cleaning' glass was discovered. A close look at 'Activ' glass today reveals the addition of a titanium dioxide active element. This additive acts as a photocatalyst that serves to break down organic matter that might stick to the glass surface and cause stains. 
The Fig. 1 Trend, effectively offers an evolution road-map to any surface. In the case of electrical contact components, for the most part manufacturers have sought to do the 'logical' thing and manufactured contact surfaces to be as smooth as possible - i.e. the first stage of the Trend. The hypothesis in effect being exploited in the 'surface texturing' experiment reported here is to examine the potential benefits of evolving surface shapes and textures that follow the Trend road-map to the second and third evolution stages.

\subsection{Materials}

Copper alloy $\mathrm{C} 101$ was chosen for the electrical contact friction experiments and two types of samples from Figure 2 were used in this study. The upper moving sample (Fig. 2 left/top) was a $20 \times 20 \times 0.5 \mathrm{~mm}$ copper foil deformed in the middle with a force of $1.5 \mathrm{kN}$ on a solid steel ball with a radius of $6 \mathrm{~mm}$ to form a hemispherical shape for point contact between the samples during the test. The same type of movable upper specimen was used in each test. The lower stationary sample (Fig. 2 left/below) consisted of 20x12×10 mm copper coupons with different surface structures. In the experiments, six different types of bottom coupons were used, each with a different texture and the corresponding surface roughness parameter $\mathrm{R}_{\mathrm{a}}$. Two of the test coupons were produced by surface polishing and four by targeted surface texturing using a milling process performed at the Advanced Manufacturing Research Centre in Shefield. The lack of a complete morphological description of the technical surfaces and the need to develop methods to characterize three-dimensional roughness were addressed by Stout et al. in the European Commission's project [29]. However, for reasons of simplicity and didactics, only the two-dimensional $R_{a}$ parameter is used in this study. The specific surface morphology was generated to create an anisotropic unidirectional texture, which was orthogonal to the sliding direction. The contacting surfaces exhibited 2D texture features i.e. grooves were aligned with the direction of the relative motion. Therefore, $2 \mathrm{D}$ roughness parameter $\mathrm{R}_{\mathrm{a}}$ was used to better represent the nature of surface texture in this contact. 
Figure 3 compares the surface morphology of the smoothest and roughest coupon, and Figure 4 shows surface profiles of flat coupons used in the fretting experiments. Periodicity of the grooves was kept at a similar level of about $450-500 \mu \mathrm{m}$, in order to minimise the spatial influence and to allow us to concentrate on the grooves amplitude. Waviness rather than roughness was taken into account during textured surfaces preparation, as it was shown previously [30] that the initial roughness will have a limited influence on surfaces under such severe fretting conditions, and will change within the first few hundreds of cycles. Surface measurements were made with the WYKO white light interferometer.

\subsection{Fretting setup}

In this study, a special shaker driven contact wear assembly designed and built at the School of Mechanical Engineering at the University of Leeds was used (Fig. 5). All experiments were performed at a frequency of $30 \mathrm{~Hz}$, under a normal load of $7 \mathrm{~N}$, under laboratory conditions at a temperature of $22^{\circ} \mathrm{C}$ and a relative humidity of between $40 \%$ and $55 \%$. The tests were performed under three different displacement amplitudes of $\pm 10 \mu \mathrm{m}$, $\pm 20 \mu \mathrm{m}$ and $\pm 30 \mu \mathrm{m}$. These amplitudes correspond to the proportion of periodicity of the surface morphologies produced. The lower sample has been positioned so that the upper sample slides on the textured surface.

\subsection{Contact resistance measurements}

In this study, the four-wire resistance measurement technique (also called Kelvin sensor) was used to measure contact resistance during friction experiments. A constant current of 5 $\mathrm{mA}$ was applied, and the schematic diagram of the friction circuit structure is shown in Fig. 6. The contact resistance as a function of friction cycles was recorded for each test, and 100 $\mathrm{m} \Omega$ was the assigned point as the failure criterion (electrical contact failure), and the tests were stopped when the resistance exceeded this value, Fig. 7.

\section{Results and Discussion}


Figures 8 to 10 show the results of friction tests with three different displacement amplitudes. The results shown in Figure 8 were obtained from tests conducted at $\pm 10 \mu \mathrm{m}$ for six coupons of different surface roughness, and the results shown in Figure 9 and 10 were obtained from tests conducted at $\pm 20 \mu \mathrm{m}$ and $\pm 30 \mu \mathrm{m}$ displacement amplitude respectively.

Figure 8 shows that the coupon with the highest roughness gives better results than other samples under $\pm 10 \mu \mathrm{m}$ displacement amplitude tests. Higher peaks and wider valleys provided more space for wear particles that accumulated without separating the paired surfaces, delaying contact resistance. It can also be observed that the distribution of experimental data is proportional to the surface roughness.

Friction tests with a displacement amplitude of $\pm 10 \mu \mathrm{m}$ resulted in better electrical contact performance than the $\pm 20 \mu \mathrm{m}$ and $\pm 30 \mu \mathrm{m}$ tests. A lower displacement amplitude led to lower energy dissipation in the contact and therefore to fewer wear particles.

It has been shown that metallic materials subjected to alternating sliding tend to generate a specific transformed layer on the top surface [31]. This layer, called a tribologically transformed structure (TTS), has a particular nanocrystalline structure corresponding to the chemical composition of the primary material. Under successive fretting cycles TTS is fragmented and a wear scar becomes saturated with debris. Wear debris is then subjected to the progressive oxidation process and, as a result, sliding surfaces are separated by a film of fully oxidized particles leading to an increase of contact electrical resistance.

The influence of surface geometry on the fretting corrosion process has not yet been studied in detail. However, it is known that high surface quality promotes friction damage [32].

Kubiak et al. [30, 33-35] report that surface geometry influences friction conditions due to the increased contact force on rough surfaces [36]. This makes it possible to control the friction between the partial slip (only the outer contact area is exposed to the slip, while the central area remains in an adhesive state) and the total slip (the entire contact surface is exposed to the slip). The integral slip with larger displacement amplitudes is not desirable for the service 
life of the electrical contacts, as much more energy is dissipated into the contact surface, which promotes intensive formation of wear particles.

In previous studies [37-38], it has been shown that copper under friction loading can cause the material to harden in the contact area with a low volume of wear. This can also be confirmed in this study with very low wear, as shown in Fig. 11, noting that the wear parts are uniformly distributed over the highly polished surface, resulting in separation of the electrical contact, In contrast, on the structured surfaces, debris deposition occurs mainly in the valleys of the applied pattern, and as a result the contact points remaining free of foreign bodies. On structured surfaces, the local contact pressure at the tops of the asperities remains much higher, which can lead to a hardening process and the formation of TTS. However, wear debris can be easily removed from the contact and the resistance in the contact remains low, which extends the life of the contact. Higher roughness and texture will result in higher local contact pressure. For most electrical connectors used in the automotive sector, the relative displacement remains below $10 \mu \mathrm{m}$, so the conditions remain relevant for real applications.

\section{Conclusions}

We have used TRIZ methodology to identify surface texturing as a viable option to increase durability of automotive electrical connectors. The potential benefits were identified by identifying the logical next stages of surface shapes and textures evolution that follow the TRIZ trend road-map.

We have experimentally demonstrated that it is possible to control the service life of the electrical contact under fretting corrosion conditions through the applied surface structure. It has also been shown that the surface with the texture applied has a lower electrical resistance than a relatively smooth and polished surface. Especially with a displacement 
amplitude of $\pm 10 \mu \mathrm{m}$, the number of cycles to failure of textured samples (13 $\left.\mu \mathrm{m} R_{a}\right)$ increased more than 20 times compared to flat samples (0.09 and $0.75 \mu \mathrm{m} \mathrm{R}_{\mathrm{a}}$ surfaces). Increase of amplitude from $\pm 10 \mu \mathrm{m}$ to $\pm 20 \mu \mathrm{m}$ and $\pm 30 \mu \mathrm{m}$ accelerated fretting-corrosion degradation of components with applied textures. A higher displacement amplitude is associated with a higher amount of wear particles in the contact surface, resulting in an accelerated accumulation of the insulating oxide layer between the surfaces.

Knowledge of the influence of surface texture and displacement amplitude on interface resistance can be effectively used in the design process of electrical connectors exposed to fretting corrosion deterioration. This study focused on a risk analysis of electrical connectors in the automotive industry from a technical point of view. Another context of this study is that of cindynics (the science of risk analysis) in the tribological environment, a subject pursued by the authors.

\section{Acknowledgements}

We would like to acknowledge a contribution to this study from MSc and visiting students in School of Mechanical Engineering at the University of Leeds: Tressia Hobeika, Franck Thirion and Damian Jozefczyk.

\section{References}

1. G. Bolger, The selection of automotive connectors, Senior Thesis, Coventry Univ., U.K., 1997.

2. J. Swingler, J.W. McBride, Proc. 19th Int. Conf. Electric Contact Phenom., Nuremberg, Germany, 1998, pp. 141-145.

3. R. B. Waterhouse, Fretting Corrosion, Pergamon Press, Oxford, 1972. 
4. L. Lam, J.W. McBride, Ch. Maul, J. K. Atkinson, Displacement measurement at the connector contact interface employing a novel thick film sensor, IEEE Transactions on Components and Packaging Technologies, 2006, pp.89-96.

5. R. Holm, Electric Contacts Handbook, Springer, 1958.

6. R. Holm, E. Holm, Electric Contacts: Theory and Application, Springer, 2000.

7. E. Rabinowicz, The importance of electrical contacts in tribology, Proc. Holm Semin. on Electric Contacts, Illinois Institute of Technology, Chicago, II, 1983, pp. 1-8.

8. M. Antler, Electrical effects of fretting connector contact materials: A review, Wear, Vol. 106, 1985, pp. 5-33.

9. T.G. Mathia "Contribution à l'étude des contacts électriques entre métaux en fonction de la pression et de la température". Ph.D. Thesis, Université Claude Bernard Lyon 1, 1972.

10. S. Hannel, S. Fouvry, Ph. Kapsa, Fretting sliding transition as a criterion for electrical contact performance, Wear, Vol. 249, 2001, pp. 761-770.

11. P. Jedrzejczyk, S. Chad, S. Fouvry, P. Chalandon, Impact of the nickel interlayer on the electrical resistance of tin-tin interface submitted to fretting loading, Surface and Coatings Technology, Vol. 203, 2009, pp. 1624-1628.

12. J.W. McBride, C. Maul, On definition of intermittency phenomena in electrical connectors during low frequency fretting. Tribology - Materials, Surfaces \& Interfaces, 2, (1), pp. 5056.

13. J.W. McBride, The relationship between surface wear and contact resistance during the fretting of in-vivo electrical contacts. IEEE Transactions on Components and Packaging Technologies, 31, (3), pp. 592-600.

14. Y.-Z. Lam, Ch. Maul, J.W. McBride, Temperature, humidity and pressure measurement on automotive connectors. IEEE Transactions on Components and Packaging Technologies, 29, (2), 2006, pp. 333-340.

15. Y.W. Park, G.N.K. Ramesh Bapu, K.Y. Lee, The influence of current load on fretting of electrical contacts, Tribology International, Vol. 42, 2009, pp. 682-689. 
16. Y.W. Park, G.N.K. Ramesh Bapu, K.Y. Lee, Evaluation of surface characteristics under fretting of electrical contacts: Removal behaviour of hot dipped tin coating, Applied Surface Science, Vol. 255, 2009, pp. 4434-4442.

17. T.S.N. Sankara Narayanan, Y.W. Park, K.Y. Lee, Fretting corrosion of lubricated tinplated contacts, Industrial Lubrication and Tribology, Vol. 50, 2008, pp. 233-241.

18. Y.W. Park, K.Y. Lee, Development of empirical equations for fretting-corrosion failuretime of tin-plated contacts, Wear, Vol. 265, 2008, pp. 756-762.

19. Y.W. Park, T.S.N. Sankara Narayanan, K.Y. Lee, Fretting corrosion of tin-plated contacts, Tribology International, Vol. 41, 2008, pp. 616-628.

20. Y.W. Park, G.N.K. Ramesh Bapu, K.Y. Lee, Fretting corrosion characteristics of electrodeposited and hot dipped tin coating contacts, Surface and Coatings Technology, Vol. 202, 2008, pp. 3164-3174.

21. T.S.N. Sankara Narayanan, Y.W. Park, K.Y. Lee, Fretting corrosion of lubricated tin plated copper alloy contacts: Effect of temperature, Tribology International, Vol. 41, 2008, pp. 87-102.

22. Y.W. Park, G.N.K. Ramesh Bapu, K.Y. Lee, Studies of tin coated brass contacts in fretting conditions under different normal loads and frequencies, Surface and Coatings Technology, Vol. 201, 2007, pp. 7939-7951.

23. Y.W. Park, T.S.N. Sankara Narayanan, K.Y. Lee, Fretting corrosion of tin-plated contacts: Evaluation of surface characteristics, Tribology International, Volume 40, Issue 3, March 2007, Pages 548-559,

24. Y.W. Park, T.S.N. Sankara Narayanan, K.Y. Lee, Effect of temperature on the fretting corrosion of tin plated copper alloy contacts, Wear, Vol. 262, 2007, pp. 320-330.

25. T.S.N. Sankara Narayanan, Y.W. Park, K.Y. Lee, Fretting-corrosion mapping of tinplated copper alloy contacts, Wear, Vol. 262, 2007, pp. 228-233.

26. Y.W. Park, T.S.N. Sankara Narayanan, K.Y. Lee, Effect of fretting amplitude and frequency on the fretting corrosion behaviour of tin plated contacts, Surface and Coatings Technology, Vol. 201, 2006, pp. 2181-2192. 
27. G. Altshuller, The Innovation Algorithm: TRIZ, Systematic Innovation And Technical Creativity, Technical Innovation Center, Worcester, MA, 1st Edition, 1999.

28. D.L. Mann, Hands-On Systematic Innovation, 2nd Edition, IFR Press, 2007.

29. K. Stout, L. Blunt, W. Dong, E. Mainsah, N. Luo, T. Mathia, P. Sullivan, H. Zahouan, Development of Methods for Characterisation of Roughness in Three Dimensions, Butterworth-Heinemann, $1^{\text {st }}$ Edition, 2000.

30. K.J Kubiak, M. Bigerelle, T.G. Mathia, A. Dubois, L. Dubar, Dynamic evolution of interface roughness during friction and wear processes, Wiley, Scanning, Vol. 36, 2014, pp. 30-38.

31. Z. R. Zhou, E. Sauger, J. J. Liu, L. Vincent, Nucleation and early growth of tribologically transformed structure (TTS) induced by fretting, Wear, Vol. 212, 1997, pp. 50-58.

32. G.W. Stachowiak, A.W. Batchelor, Engineering Tribology, Elsevier, Oxford, 3rd Ed., 2005.

33. G. Fischer, M. Bigerelle, K.J. Kubiak, T.G. Mathia, Z.Khatir, K.Anselme, Wetting of anisotropic sinusoidal surfaces - experimental and numerical study of directional spreading, Surface Topography Metrology and Properties, Vol. 2, 2014, 044003.

34. K.J. Kubiak, T.G. Mathia, Anisotropic wetting of hydrophobic and hydrophilic surfaces modelling by Lattice Boltzmann Method, Procedia Engineering, Vol. 79, 2014, pp.45-48.

35. K.J. Kubiak, T.G. Mathia, Influence of roughness on contact interface in fretting under dry and boundary lubricated sliding regimes, Wear, Vol. 267, 2009, pp. 315-321.

36. K.J. Kubiak, T.G. Mathia, M. Bigerelle, Influence of roughness on ZDDP tribofilm formation in boundary lubricated fretting, Tribology Materials Surfaces and Interfaces, Vol 6, No 4, 2012, pp. 182-188.

37. T. Liskiewicz, K. Kubiak, T. Comyn, Nano-indentation mapping of fretting-induced surface layers, Tribology International, Vol. 108, 2017, pp. 186-193.

38. Y. Liu, T. W. Liskiewicz, B. D. Beake, Dynamic changes of mechanical properties induced by friction in the Archard wear model, Wear, Vol. 428-429, 2019, pp. 366-375. 
Fig. 1. TRIZ, Surface segmentation evolution trend pattern.

Fig. 2. Left: The hemispherical (top) and flat (bottom) samples used in fretting experiments; Right: Schematic morphological configuration of test samples.

Fig. 3. Left: Surface morphology of a sample polished with 1200 grade sand paper and mirror finished with a diamond paste. Right: milled sample. See Fig. 4 for detailed metrological values.

Fig. 4. Surface profiles of flat (bottom) coupons used in the fretting experiments; a) sample polished with 1200 grade sand paper and mirror finished with a diamond paste - surface roughness $R_{a}=0.09 \mu \mathrm{m}$; b) sample randomly polished with 120 grade sand paper - surface roughness $\left.R_{a}=0.75 \mu \mathrm{m} ; c\right)$ sample milled - surface roughness $R_{a}=2.09 \mu \mathrm{m} ; \mathrm{d}$ ) sample milled - surface roughness $R_{a}=5.94 \mu \mathrm{m} ; \mathrm{e}$ ) sample milled - surface roughness $R_{a}=9.51$ $\mu \mathrm{m}$; f) sample milled - surface roughness $R_{a}=13.76 \mu \mathrm{m}$. Note different scales of both axes. Fig. 5. Diagram of the fretting wear tribometer.

Fig. 6. The geometrical configuration of the hemispherical and flat samples with the four point electrical circuit applied to measure the contact resistance.

Fig. 7. Establishing the electrical contact failure criterion; in this case observed at $14800^{\text {th }}$ fretting cycle.

Fig. 8. Number of fretting cycles to failure ( $100 \mathrm{~m} \Omega$ failure criterion) as a function of bottom coupon surface roughness. Displacement amplitude applied $\pm 10 \mu \mathrm{m}$.

Fig. 9. Number of fretting cycles to failure ( $100 \mathrm{~m} \Omega$ failure criterion) as a function of bottom coupon surface roughness. Displacement amplitude applied $\pm 20 \mu \mathrm{m}$.

Fig. 10. Number of fretting cycles to failure ( $100 \mathrm{~m} \Omega$ failure criterion) as a function of bottom coupon surface roughness. Displacement amplitude applied $\pm 30 \mu \mathrm{m}$. 
Fig. 11. Wear debris morphology. Left: polished sample with 1200 grade sand paper and mirror finished with a diamond paste - surface roughness $R_{a}=0.09 \mu \mathrm{m}$; Right: milled sample, surface roughness $R_{a}=2.09 \mu \mathrm{m}$. 


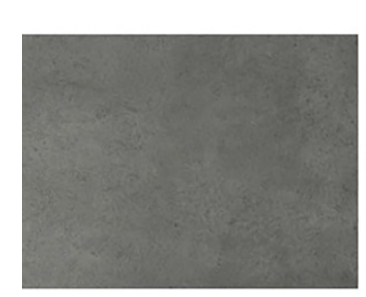

Smooth

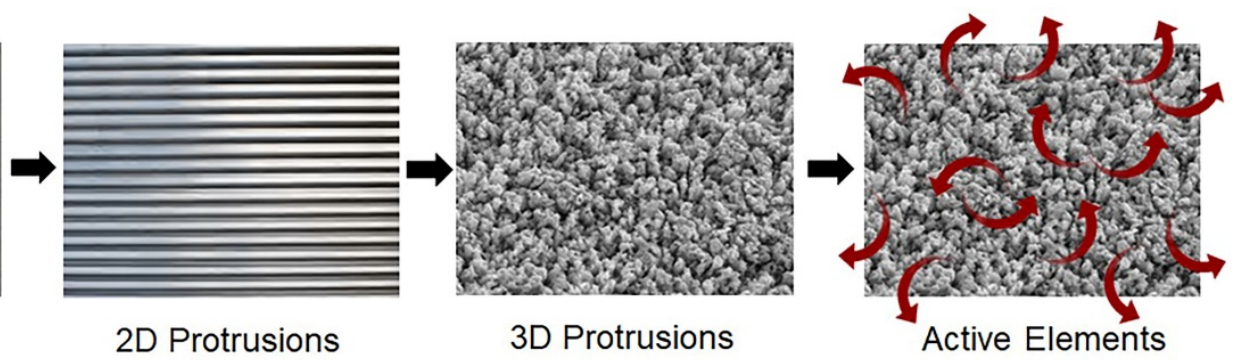



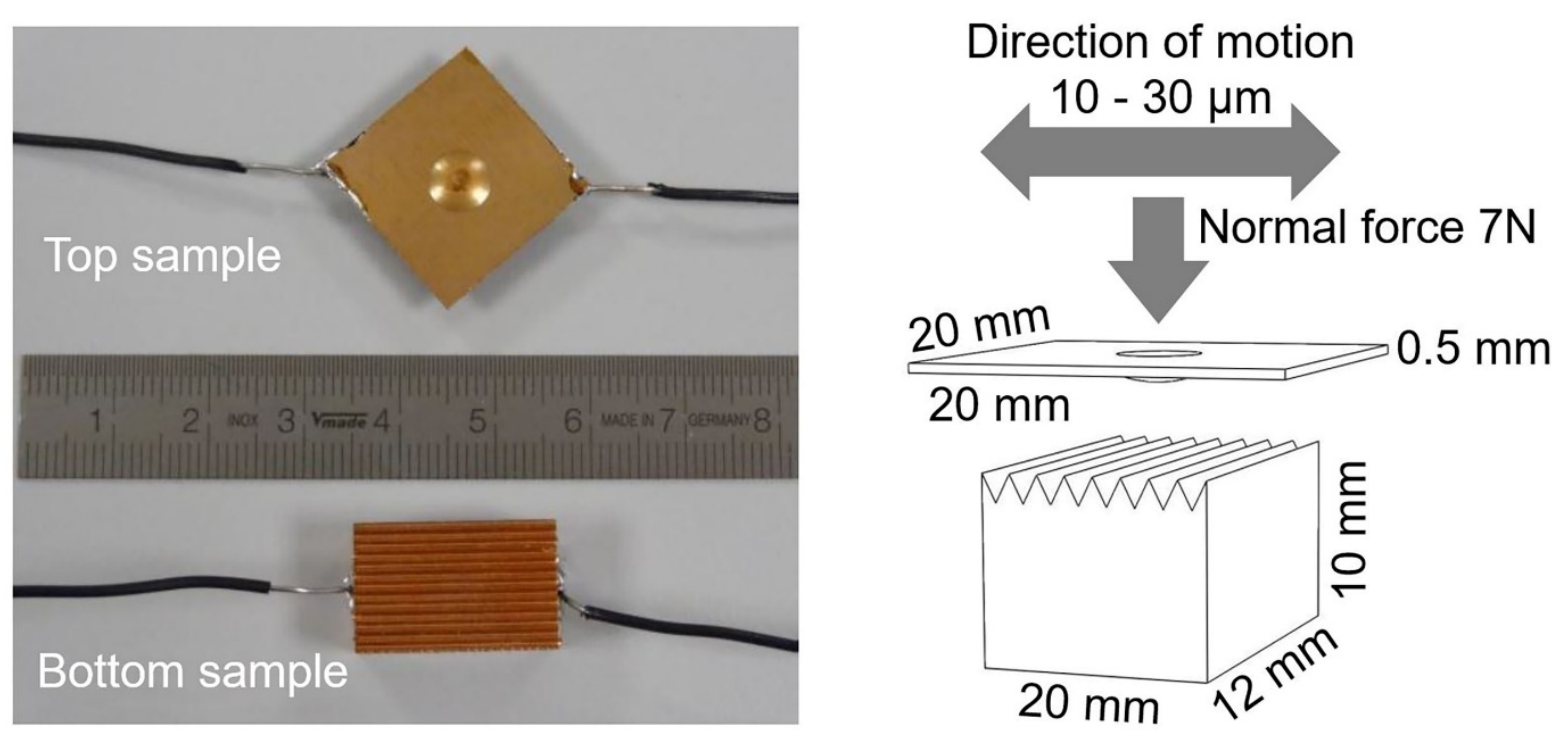

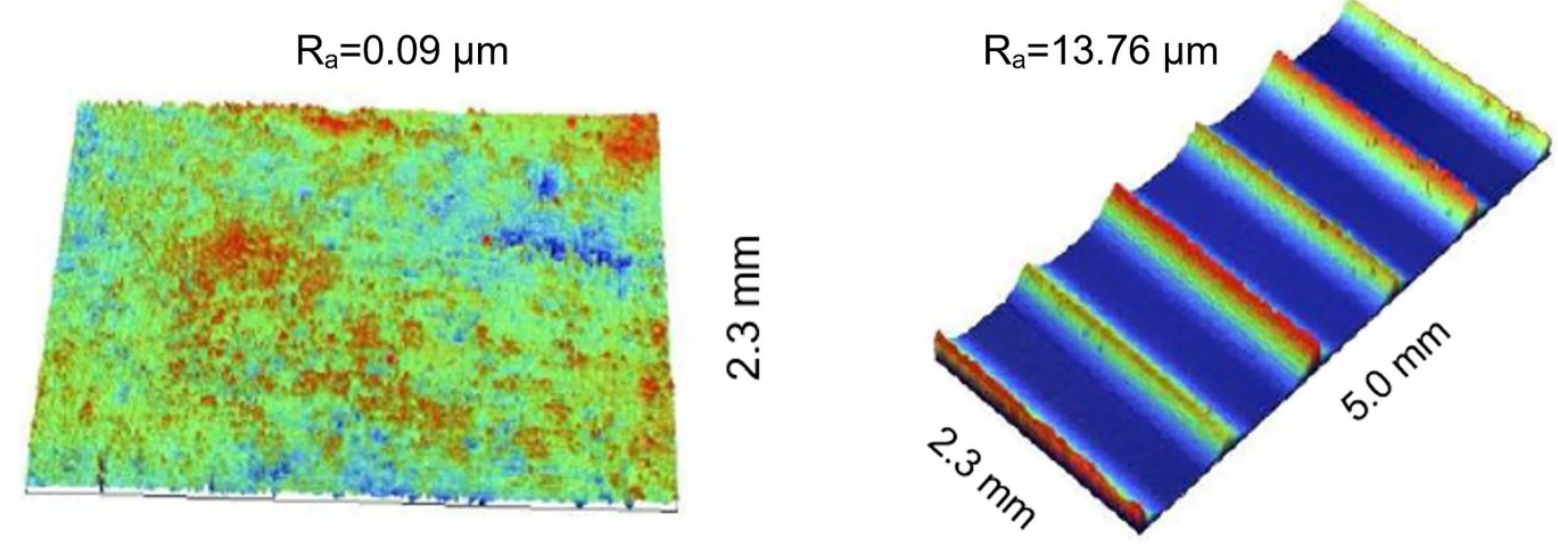

$5.0 \mathrm{~mm}$ 

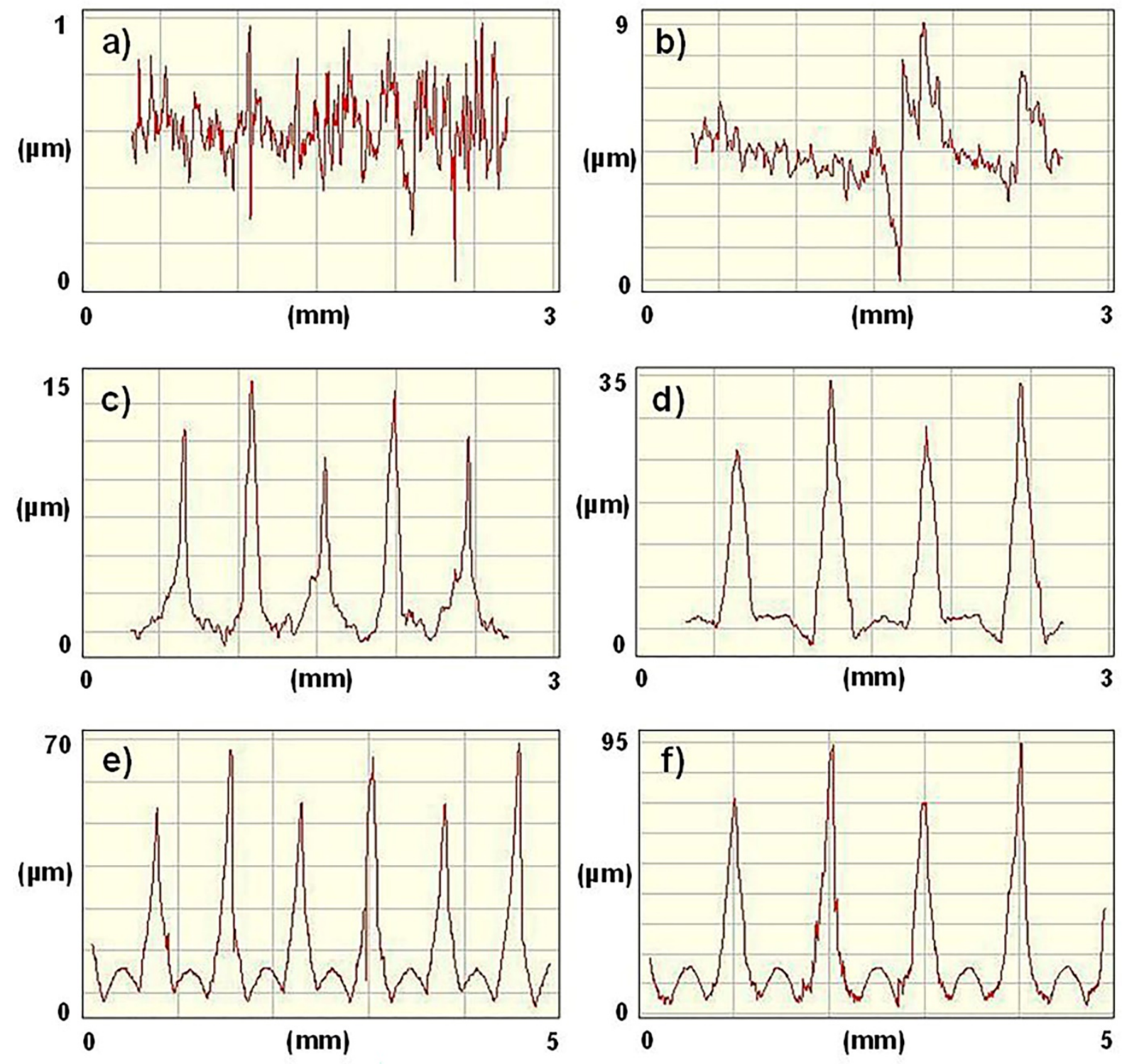


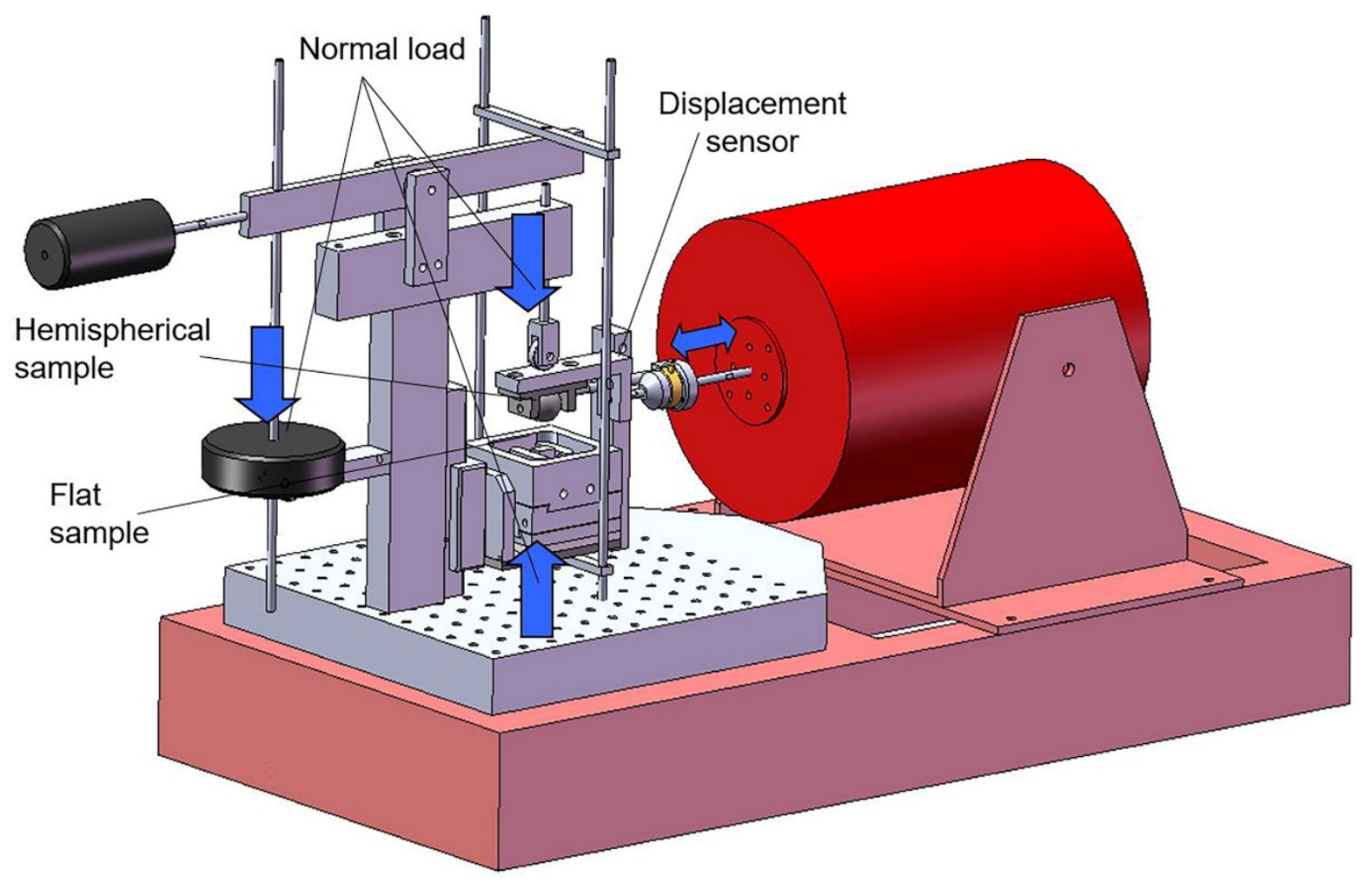


Hemisphere specimen

DC constant current ( $0.5 \mathrm{~mm}$ thickness, $6 \mathrm{~mm}$ radius)

power supply

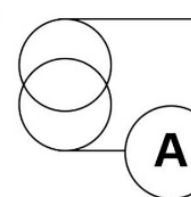

Ampere meter

Flat textured specimen

Volt meter 


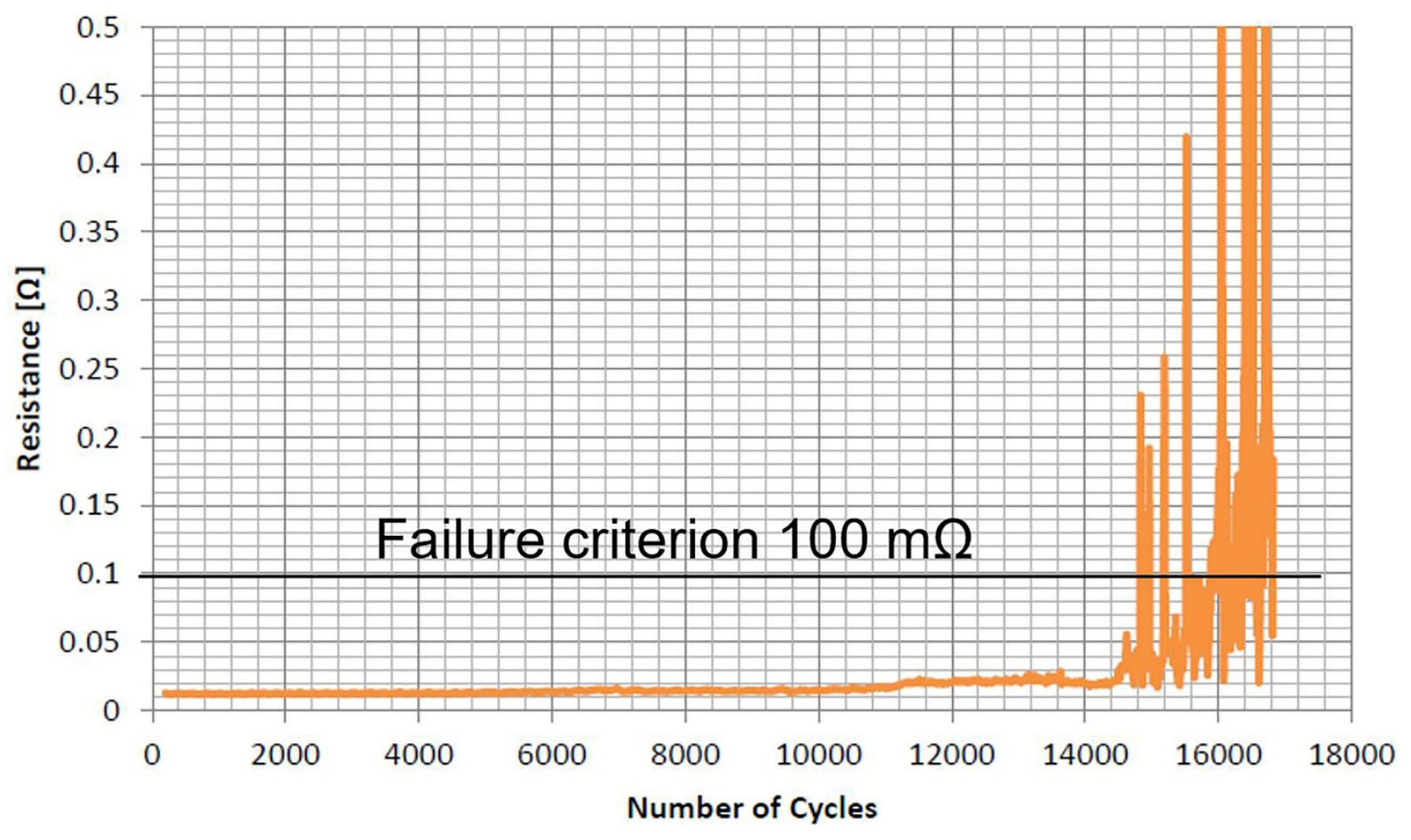




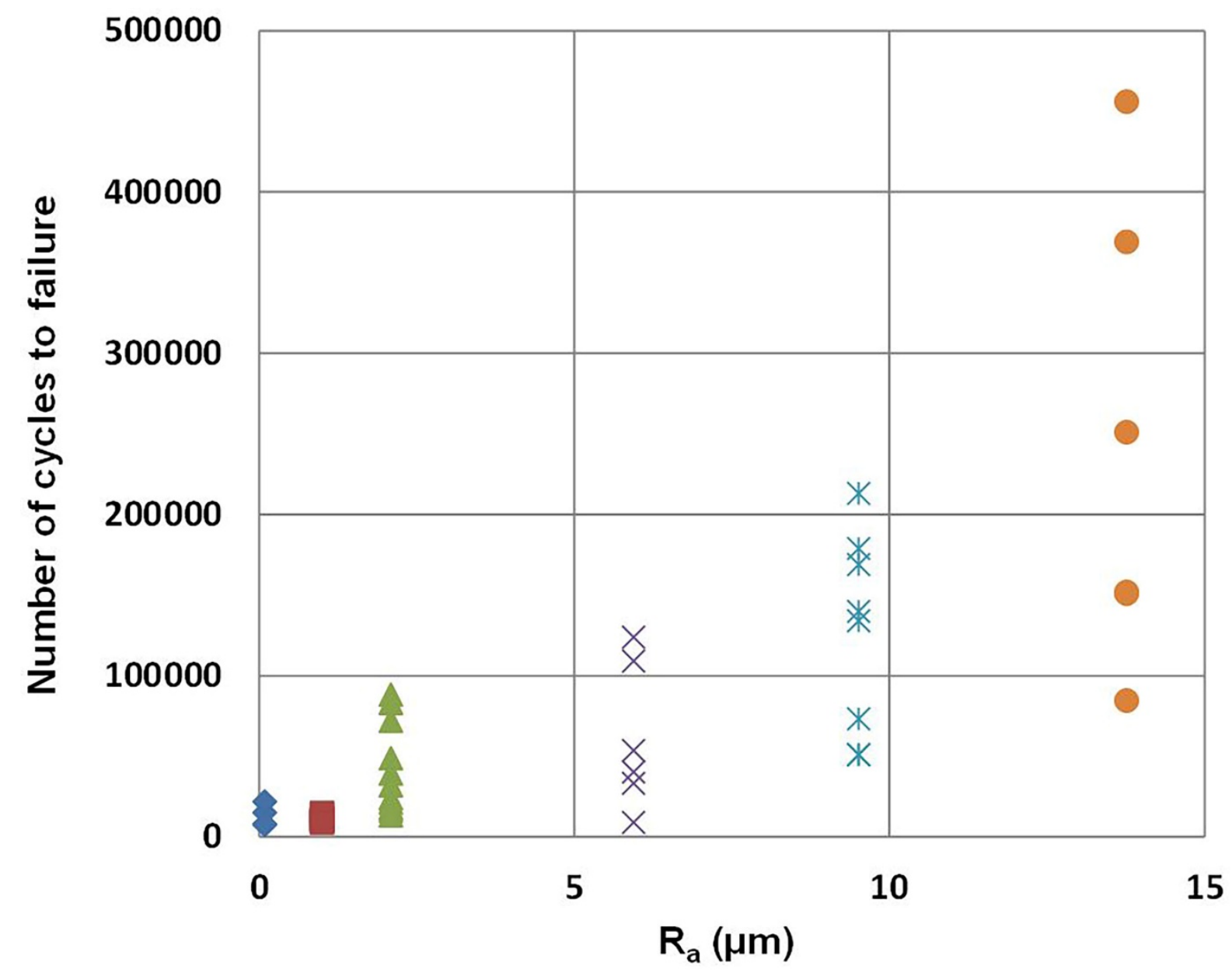




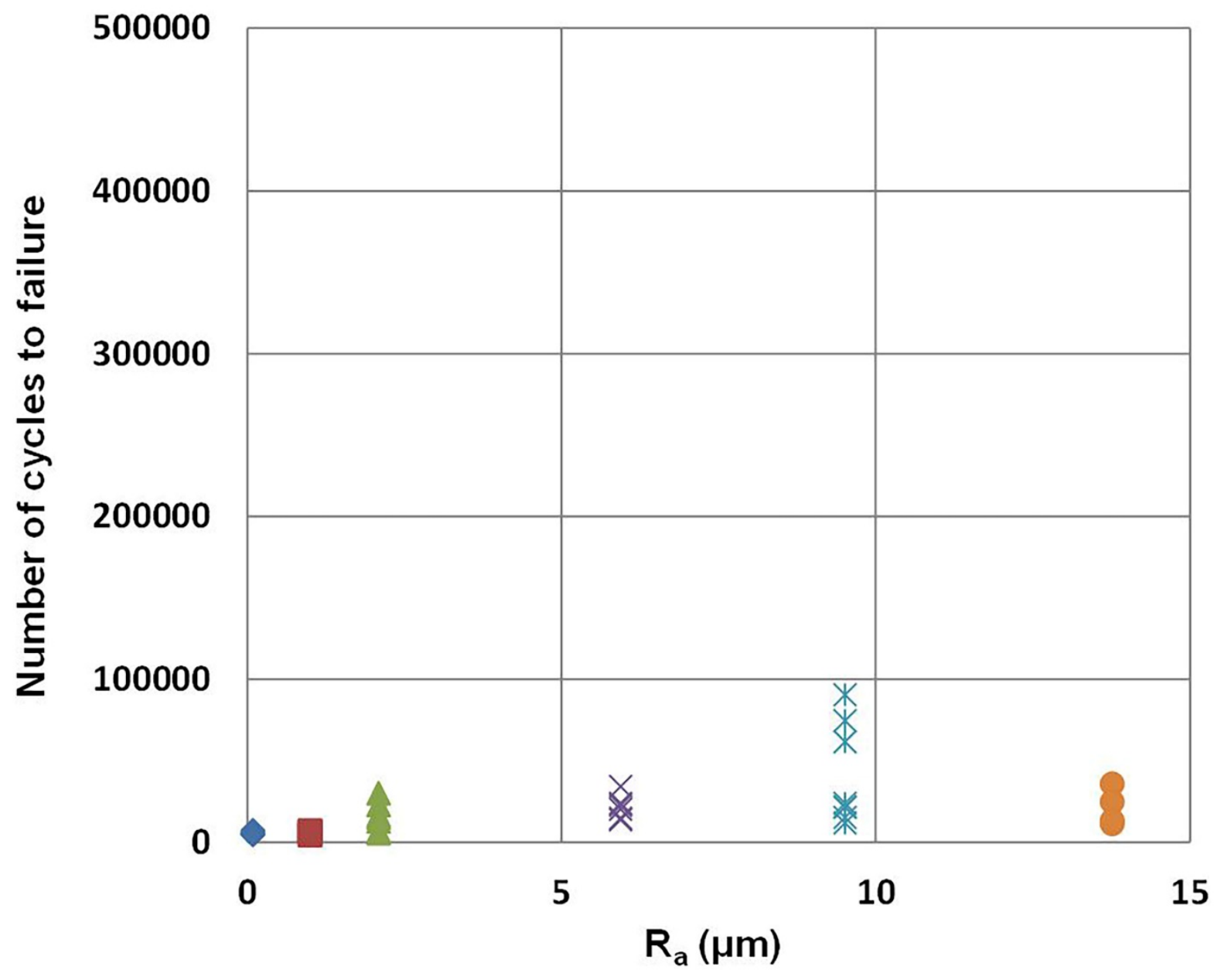




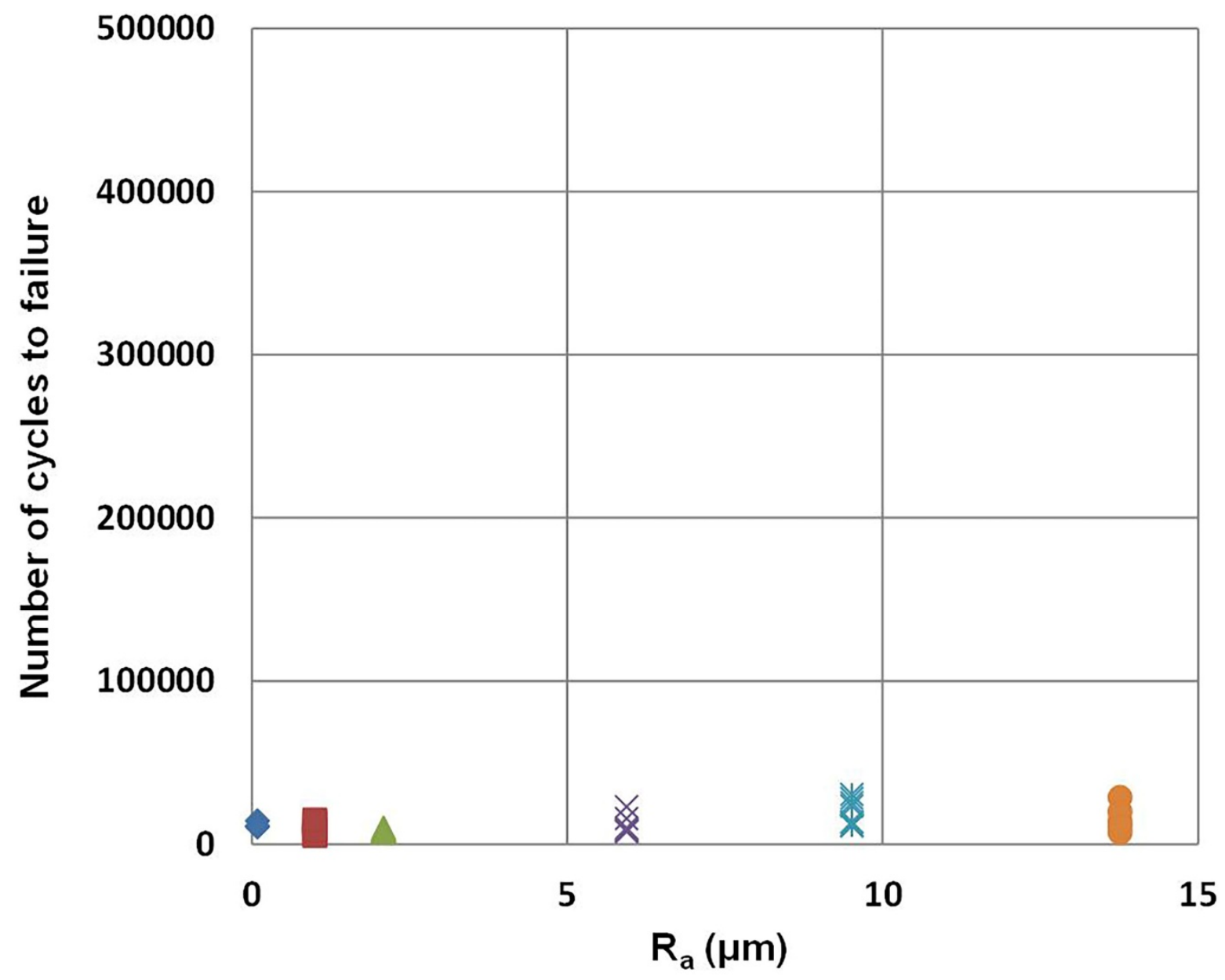



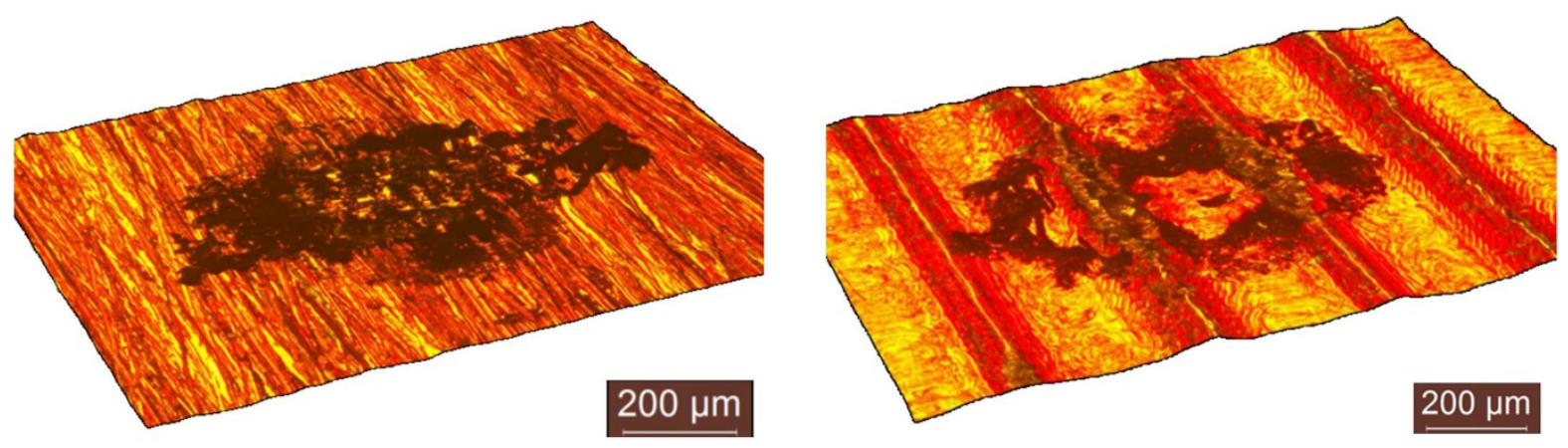